\title{
Optimization of Cultural Conditions for Production of Antibacterial Metabolites from Streptomyces coelicoflavus BC 01
}

\author{
Kothagorla Venkata RAGHAVA RAO*, Dadi BHASKARA RAO, \\ Botcha SATYANARAYANA, Tamanam RAGHAVA RAO
}

Department of Biochemistry, Andhra University, Visakhapatnam 530003,AndhraPradesh, India; kv.raghavarao@yahoo.co.in ("correspondingauthor)

\begin{abstract}
The aim of the present study was to optimize various cultural conditions for the production of antibacterial metabolites by Streptomyces coelicoflavus BC 01 isolated from mangrove soil, Visakhapatnam, Andhra Pradesh, India. The effect of various factors such as carbon and nitrogen sources, different concentrations of $\mathrm{NaCl}$ and $\mathrm{K}_{2} \mathrm{HPO}_{4}$, different temperature, $\mathrm{pH}$, incubation time and agitation on antibacterial metabolites production were studied. The production of antibacterial metabolites by the isolate Streptomyces coelicoflavus $\mathrm{BC} 01$ was greatly influenced by the cultural conditions. Glucose $(1.2 \%)$ and soya bean meal (1\%) seemed to be the best carbon and nitrogen source respectively, followed by $\mathrm{NaCl}(1 \%)$ and $\mathrm{K}_{2} \mathrm{HPO}_{4}(0.25 \%)$. Maximum production of antibacterial metabolites was observed at a temperature of $30{ }^{\circ} \mathrm{C}$, with $\mathrm{pH} \mathrm{7.2,} \mathrm{at} 160 \mathrm{rpm}$ for $96 \mathrm{hrs}$. These optimized parameters can be further useful to design a fermentation medium to achieve maximum yield of antibacterial metabolites from Streptomyces coelicoflavus BC 01.
\end{abstract}

Keywords: optimization, antibacterial metabolites, cultural conditions, Streptomyces coelicoflavus, fermentation medium

\section{Introduction}

Actinomycetes are the most widely distributed group of microorganisms in natural and manmade environment. They play an important role in producing secondary metabolites of novel structures, which includes antibacterial, antifungal, antitumor, antiprotozoic and antiviral properties, vitamins, enzymes etc. (Priya et al., 2012). As on today, $70 \%$ of the known antibiotics are isolated from actinomycetes and among them, two thirds are produced from Streptomyces (Miyadoh, 1993). A number of clinically important antibiotics, as well as widely used drugs against common diseases, have been derived from Streptomyces (Bibb, 2005). Streptomyces are supposed to produce about $75 \%$ of commercially and medically useful antibiotics (Usha et al., 2013). Streptomyces species are widely recognized as industrially important microorganisms because of their ability to produce different kinds of novel secondary metabolites (Solanki et al., 2005).

The production of antimicrobial metabolites depends on the nutritional and physiological conditions of the microorganisms. Hence, designing an appropriate culture medium is very important, as the medium composition can significantly affect the yield of the antimicrobial metabolites. Media components and their optimum levels are essential for the production of antimicrobial metabolites by microorganisms. The production of antibiotics through fermentation is influenced by the concentration and type of carbon, nitrogen, phosphorous sources, as well as trace elements and also variable conditions like temperature, $\mathrm{pH}$ and aeration (Lin et al., 2010; Ruiz et al., 2010; Sanchez et al., 2010). In addition to nutrients, medium may also contain various inhibitors of microbial growth and biosynthesis, which may affect the antibiotic production. For improving the antibacterial metabolites from Streptomyces sp., medium components and environmental conditions play an initial and vital role.

The present study was undertaken to investigate the effect of different nutrients and cultural conditions on the production of antibacterial metabolites by the isolate Streptomyces coelicoflavus BC 01 and to determine the optimal conditions for maximum production.

\section{Materials and methods}

\section{Isolation of actinomycetes}

The actinomycetes strain BC 01 was isolated from mangrove soil Visakhapatnam, Andhra Pradesh, India by using serial dilution plating techniques on yeast extract, malt extract, glucose (ISP-2) agar slants at $28{ }^{\circ} \mathrm{C}$ to get good sporulation and stored under refrigeration at $4{ }^{\circ} \mathrm{C}$ until further use.

Morphological, cultural and physiological characteristics of the strain were studied by using International Streptomyces Project (ISP) media recommended by Shirling and Gottlieb (1966). The $16 \mathrm{~S}$ rRNA gene partial sequence of the strain $\mathrm{BC} 01$ was deposited in NCBI nucleotide database with Accession No JX126485 and the sequence was correlated with genus Streptomyces by using BLASTN. A phylogenetic tree was reconstructed by using neighborjoining method. The results stipulate that the BC 01 strain closely resembles with the genus $S$. coelicoflavus NBRC 
152

15399T (AB184650). By comparing the phenotypic and phylogenetic data, it was confirmed that the strain BC 01 belongs to Streptomyces coelicoflavus (Rao and Rao, 2013).

The production of antibacterial metabolite yield by the Streptomyces coelicoflavus BC 01 strain was optimized by using different nutritional and environmental parameters such as carbon, nitrogen, $\mathrm{NaCl}, \mathrm{pH}$, temperature, agitation and aeration.

\section{Testmicroorganisms}

All test organisms employed in the present investigation were procured from Microbial Type Culture Collection (MTCC), Chandigarh, India. The test organisms used for the determination of antibacterial activity are Staphylococcus aureus (MTCC 3160), Bacillus subtilis (MTCC 441), Bacillus cereus (MTCC 430), Pseudomonas aeruginosa (MTCC 424), Escherichia coli (MTCC 443) and Proteus vulgaris (MTCC 426).

\section{Inoculum preparation}

Five $\mathrm{ml}$ of sterile $0.9 \% \mathrm{NaCl}$ solution were added to a 7 day old, well sporulated, slant of the culture. The spores were scraped from the slant into sterile saline solution and the resulting spore suspension, at $10 \%$ level, was aseptically transferred into a $500 \mathrm{ml}$ Erlenmeyer flask containing $200 \mathrm{ml}$ of inoculum medium. The inoculum medium comprises $(\mathrm{g} / \mathrm{L})$ : glucose 10.0 ; soya bean meal 10.0; $\mathrm{NaCl} 5.0 ; \mathrm{CaCO}_{3}$ 5.0, with $\mathrm{pH}$ 7.0. The inoculated flasks were kept in an orbital shaker $(120 \mathrm{rpm})$ at $28^{\circ} \mathrm{C}$ for $48 \mathrm{hrs}$. The contents of the flasks were centrifuged at 3,000 rpm for 10 minutes, followed by the supernatant removal. The cell pellet was washed thoroughly and suspended in $0.9 \% \mathrm{NaCl}$ solution. This cell suspension was used as inoculum.

\section{Submerged fermentation}

Five ml of inoculum ( $5 \mathrm{mg} / \mathrm{ml}$ dry cell weight) were added to $200 \mathrm{ml}$ of production medium in $500 \mathrm{ml}$ Erlenmeyer flask. Pridham and Gottlieb's inorganic salts medium (Pridham and Gottlieb, 1948) was used as the production medium base. It was supplemented with different carbon and nitrogen sources to study their effect on growth and antibacterial metabolite production. The flasks were kept at $28{ }^{\circ} \mathrm{C}$ on an orbital shaker $(120 \mathrm{rpm})$ for $96 \mathrm{hrs}$. At the end of the fermentation process, 5 $\mathrm{ml}$ broth were collected and centrifuged at 3,000 rpm for 15 minutes. The clear mycelia free culture supernatant was used for determination of antibiotic assay by using agar well diffusion method.

\section{Effects of various carbon sources}

Effect of various carbon sources on growth and antibiotic production was studied by incorporating them at $1 \%(\mathrm{w} / \mathrm{v})$ level into the Pridham and Gottlieb's inorganic salts medium. The carbon sources used were glucose, fructose, galactose, sucrose, mannose, sorbitol, inositol, xylose, arabinose and glycerol. In order to optimize the concentration of the best carbon source for maximum growth and antibacterial metabolite production, different concentrations of $0.2,0.4$, $0.6,0.8,1.0,1.2,1.4,1.6,1.8$ and $2.0 \mathrm{~g} / 100 \mathrm{ml}$ were added to the production medium.

\section{Effects of various nitrogen sources}

The influence of various nitrogen sources on growth and antibiotic production was studied by adding inorganic nitrogen sources and organic nitrogen sources at $0.4 \%(\mathrm{w} / \mathrm{v})$ level into the Pridham and Gottlieb's inorganic salts medium. The optimized carbon source was used for further investigations. The inorganic compounds used were ammonium citrate, ammonium nitrate, ammonium sulphate, potassium nitrate and sodium nitrate. The organic nitrogen compounds employed were soya bean meal, peptone, beef extract, yeast extract, tryptone, amino acids-leucine, histidine, methionine, asparagine and glutamate. The concentrations of optimized nitrogen source (soya bean meal) used to determine the optimum concentration for growth and antibiotic production was $0.2,0.4,0.6,0.8,1.0$, $1.2,1.4,1.6,1.8$ and $2.0 \mathrm{~g} / 100 \mathrm{ml}$. Each concentration of soya bean meal was incorporated into the Pridham and Gottlieb's inorganic salts medium.

\section{Effects of different $\mathrm{K}_{2} \mathrm{HPO}_{4}$ concentrations}

In order to optimize the concentration of $\mathrm{K}_{2} \mathrm{HPO}_{4}$ for antibiotic production, different concentrations of $0.05,0.1,0.15,0.2,0.25,0.3,0.35,0.4,0.45$ and 0.5 $\mathrm{g} / 100 \mathrm{ml}$ were incorporated into the production medium.

\section{Effects of different $\mathrm{NaCl}$ concentrations}

Different $\mathrm{NaCl}$ concentrations $0.2,0.4,0.6,0.8,1.0$, $1.2,1.4,1.6,1.8$ and $2.0 \mathrm{~g} / 100 \mathrm{ml}$ were incorporated into the Pridham and Gottlieb's inorganic salts medium to determine the optimum concentration of $\mathrm{NaCl}$ for antibiotic production.

\section{Effects of incubation temperature}

Inoculated production medium was incubated at different temperatures of $15,20,25,30,35,40,45$ and $50{ }^{\circ} \mathrm{C}$ for $96 \mathrm{hrs}$ to determine the optimum incubation temperature for antibiotic production.

\section{Effects of initial $p H$}

The production media were adjusted to different initial $\mathrm{pH}$ values of $3.2,4.2,5.2,6.2,7.2,8.2,9.2,10.2$ and 11.2 in order to study the effect of initial $\mathrm{pH}$ of the medium on growth and antibiotic production.

\section{Effects of incubation period}

In order to investigate the optimal incubation period for maximum antibacterial metabolite production, the flasks with the mediums were inoculated and incubated at $30^{\circ} \mathrm{C}$ for every 12 hours up to 144 hrs.

\section{Effects of agitation}

The effects of agitation on growth and antibacterial metabolite production were investigated by conducting the fermentation at different agitation speeds of 60,80 , $100,120,140,160,180,200,220$ and $240 \mathrm{rpm}$ at $30^{\circ} \mathrm{C}$ for 96 hrs consecutively.

\section{Growth measurements}

The growth of the organism was represented by the dry weight of the mycelium. The contents of the culture flask were filtered through a previously weighed dry Whatmann No. 1 filter paper, washed twice with distilled water. The filter paper together with the mycelial mass was dried in a hot air oven at $80{ }^{\circ} \mathrm{C}$ for 18-24 hrs. At the end, the filter paper was weighed. 


\section{Antibiotic assay}

Culture samples $(1 \mathrm{ml})$ were taken at specified time intervals, centrifuged at $3,000 \mathrm{rpm}$ for $15 \mathrm{~min}$ at $4{ }^{\circ} \mathrm{C}$ and then separated into culture filtrate and mycelium. The antibiotic activities of mycelia free culture supernatant against test organisms were measured by agar well diffusion method.

\section{Statistical analysis}

All investigations were conducted in triplicates. The obtained data was exposed to standard deviation and bar diagrams were generated using Microsoft Excel 2010.

\section{Results and discussions}

Medium formulation is an essential stage for the production of specific bioactive compounds by pilot scale development and manufacturing processes. The constituents of a medium must satisfy the elemental requirements for cell biomass and metabolite production and there must be an adequate supply of energy for biosynthesis and cell maintenance. Numerous studies on the nutritional requirement for production of antibiotics and other nonessential metabolites have demonstrated that there is a relation between nutrient limitation and biosynthesis of secondary metabolite (Fisher and Sonnenshein, 1991; Vilches et al., 1990).

\section{Effects of carbon source on antibiotic production}

The optimization of the antibacterial metabolite production was carried out in batch cultures. The Streptomyces coelicoflavus BC 01 isolate was cultivated in Pridham and Gottlieb's inorganic salts medium, supplemented with different carbon sources $1 \%(\mathrm{w} / \mathrm{v})$ and their effect on growth and antibacterial metabolite yield was studied.

The Streptomyces coelicoflavus BC 01 isolate have grown well on media supplemented with different carbon sources. However, maximum antibacterial activity was obtained when media was supplemented with $1 \%(\mathrm{w} / \mathrm{v})$ glucose followed by glycerol and sorbitol. The growth of the isolate with various carbon sources was studied in terms of dry weight of the mycelium. The effect of various carbon sources on growth and antibacterial metabolite production was tabulated in Table 1 . The highest biomass production was observed with glucose $(3.2 \mathrm{mg} / \mathrm{ml})$ followed by glycerol $(2.2 \mathrm{mg} / \mathrm{ml})$ and sorbitol $(1.2 \mathrm{mg} / \mathrm{ml})$. The scanty biomass production was observed with mannose $(0.2 \mathrm{mg} / \mathrm{ml})$ followed by sucrose $(0.5$ $\mathrm{mg} / \mathrm{ml})$, inositol $(0.5 \mathrm{mg} / \mathrm{ml})$ and arabinose $(0.5 \mathrm{mg} / \mathrm{ml})$.

The maximum zone of inhibition was observed at $1 \%$ (w/v) glucose; for B. subtilis and P. vulgaris it was $33 \mathrm{~mm}$, whereas for $B$. cereus, $S$. aureus, $E$. coli and $P$. aeruginosa it was $29 \mathrm{~mm}$. The results show that among all the carbon sources used in this study, glucose exhibited the maximum antibacterial activity. Therefore, further optimization process was carried out by using different concentrations of glucose as a carbon source.

The effects of different concentrations $(0.2,0.4,0.6,0.8$, $1.0,1.2,1.4,1.6,1.8$ and $2.0 \mathrm{~g} / 100 \mathrm{ml}$ ) of glucose on growth and antibacterial metabolite production were examined. Results are shown in Fig. 1. Among all the concentrations, the maximum zone of inhibition was observed at $1.2 \mathrm{~g} / 100 \mathrm{ml}$ concentration of glucose with a biomass of $3.5 \mathrm{mg} / \mathrm{ml}$ and the maximum zone of inhibition observed were $P$. vulgaris ( 38.33 $\pm 0.94)$, E. coli $(35.66 \pm 1.24)$, B. subtilis $(35.33 \pm 0.94), P$. aeruginosa (34.66 \pm 0.94$)$, S. aureus $(34.33 \pm 1.69)$ and $B$. cereus $(33.33 \pm 1.24)$. The results suggested that $1.2 \mathrm{~g} / 100 \mathrm{ml}$ of glucose concentration was optimum for the antibacterial metabolite production. The increase of the glucose level of concentration to $1.4 \mathrm{~g} / 100 \mathrm{ml}$ lead to a reduced zone of inhibition, therefore further optimizing process was carried out by employing $1.2 \mathrm{~g} / 100 \mathrm{ml}$ of glucose as carbon source. The reduced zone of inhibition might be due to the uptake of glucose at higher concentrations than other carbon sources by the genus Streptomyces as was stated by Van Wezel et al. (2005) in case of Streptomyces coelicolor. Similarly Tarhan et al. (2011) found that antibiotic production of Streptomyces sp. M4018 was higher in glucose containing medium when compared with glycerol and starch. The same result was also obtained by Vasavada et al. (2006) who reported that the highest antibacterial activity of Streptomyces sannanensis strain RJT-1 was obtained when glucose at $1 \%(\mathrm{w} / \mathrm{v})$ was used as a carbon source, followed by xylose and arabinose. Similar findings were also reported by Pandey et al. (2005) and Ripa et al. (2009) by which glucose was proved to be the best carbon source for antibiotic production by Streptomyces kanamyceticus M27 and Streptomyces sp. RUPA-08PR respectively. The study of Jakeman et al. (2006) indicated that the addition of carbon source to the media has a strong impact on the antibiotic production by Streptomyces venezuelae. However, the high concentration of glucose in the medium was observed to decrease the growth and also the antibiotic production by Gesheva et al. (2005) and Zhu et al.

Table 1. The effects of various carbon sources on growth and antibacterial metabolite production by Streptomyces coelicoflavus BC 01

\begin{tabular}{|c|c|c|c|c|c|c|c|}
\hline \multirow{3}{*}{$\begin{array}{l}\text { Carbon Source } \\
1 \%(\mathrm{w} / \mathrm{v})\end{array}$} & \multirow{3}{*}{$\begin{array}{c}\text { Growth in dry } \\
\text { weight } \\
(\mathrm{mg} / \mathrm{ml})\end{array}$} & \multicolumn{6}{|c|}{ Zone of inhibition in $\mathrm{mm}$} \\
\hline & & \multicolumn{3}{|c|}{ Gram Positive Bacteria } & \multicolumn{3}{|c|}{ Gram Negative Bacteria } \\
\hline & & S. aureus & B. subtilis & B. cereus & E. coli & P. vulgaris & $P$. aeruginosa \\
\hline Glucose & 3.2 & 29 & 33 & 29 & 29 & 33 & 29 \\
\hline Fructose & 0.7 & 15 & 13 & 11 & 11 & 14 & 13 \\
\hline Galactose & 0.8 & 13 & 12 & 13 & 14 & 13 & 11 \\
\hline Sucrose & 0.5 & 15 & 14 & 10 & 13 & 12 & 13 \\
\hline Mannose & 0.2 & 10 & 12 & 11 & 12 & 10 & 11 \\
\hline Sorbitol & 1.2 & 14 & 15 & 13 & 14 & 14 & 12 \\
\hline Inositol & 0.5 & 13 & 15 & 12 & 12 & 11 & 13 \\
\hline Xylose & 0.6 & 11 & 12 & 10 & 12 & 13 & 11 \\
\hline Arabinose & 0.5 & 12 & 14 & 16 & 14 & 13 & 12 \\
\hline Glycerol & 2.2 & 17 & 18 & 16 & 17 & 18 & 18 \\
\hline
\end{tabular}




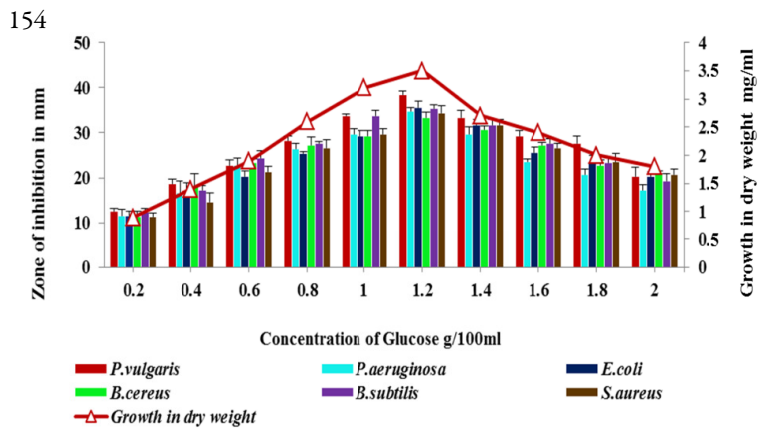

Fig. 1. Effects of glucose on growth and production of antibiotic activity against test organisms in Streptomyces coelicoflavus BC 01

(2007) in Streptoverticillium sp. 43/16 and Streptomyces viridochromogenes respectively.

\section{Effects of nitrogen source on antibiotic production}

Nitrogen source along with the carbon source play an important role in the production of antibacterial metabolites. The effects of various organic and inorganic nitrogen sources on the growth and antibacterial metabolites production were represented in Table 2. Among the various inorganic nitrogen sources, the maximum antibacterial activity was obtained by ammonium nitrate with a biomass of $2.6 \mathrm{mg} / \mathrm{ml}$, followed by ammonium sulphate with a biomass of 1.8 $\mathrm{mg} / \mathrm{ml}$. The antibacterial activity of sodium nitrate, potassium nitrate and ammonium citrate was almost equal, but vary in biomass.

Among the organic nitrogen sources, the highest antibacterial activity was attained by soya bean meal with a maximum zone of inhibition observed in $P$. aeruginosa, $B$. cereus and $P$. vulgaris $(18 \mathrm{~mm})$, whereas E. coli and B. subtilis zone of inhibition was of $17 \mathrm{~mm}$. In case of $S$. aureus the zone of inhibition was $15 \mathrm{~mm}$. At $0.4 \%(\mathrm{w} / \mathrm{v})$ of soya bean meal with a biomass of $3.2 \mathrm{mg} / \mathrm{ml}$ followed by yeast extract and beef extract with a biomass of $2.2 \mathrm{mg} / \mathrm{ml}$ and $1.8 \mathrm{mg} / \mathrm{ml}$ respectively. The lowest levels of antibacterial activity were obtained by peptone and leucine with a biomass of $1.3 \mathrm{mg} / \mathrm{ml}$ and $1.4 \mathrm{mg} / \mathrm{ml}$ respectively. Substitution of inorganic nitrogen sources with amino acids revealed that all the amino acids glutamate, asparagine, histidine tryptone and methonine showed worthy antibacterial activity, whereas leucine showed moderate antibacterial activity.

In the case of inorganic and organic nitrogen sources, soya bean meal was found to be the best for production of antibacterial metabolites. For this reason different concentrations $(0.2,0.4,0.6,0.8,1.0,1.2,1.4,1.6,1.8$ and 2.0 $\mathrm{g} / 100 \mathrm{ml}$ ) of soya bean meal were used for further optimization processes. Results are shown in Fig. 2. The highest antibacterial activity was attained at $1.0 \mathrm{~g} / 100 \mathrm{ml}$ of soya bean meal with a maximum zone of inhibition observed for E. coli $(36.66 \pm 1.24)$, S. aureus $(35.33 \pm 1.69)$, B. subtilis $(33.66 \pm 0.47)$ and $P$. vulgaris $(33.33 \pm 1.24)$, with a biomass of $3.4 \mathrm{mg} / \mathrm{ml}$. The isolate Streptomyces coelicoflavus BC 01 was optimized at $1.0 \mathrm{~g} / 100 \mathrm{ml}$ of soya bean meal. Similar results where soya bean meal increases the production of antibiotic yield were reported by Singh et al. (2009) in Streptomyces tanashiensis strain A2D, Narayana and Vijayalakshmi (2008) in Streptomyces albidoflavus, Viana et al. (2010) in Streptomyces DAUFPE 3060 and Wu et al. (2008) in Streptomyces padanus PMS-702 respectively. All these results suggest that the level of antibiotic production may be greatly influenced by the nature and type of nitrogen source supplied in the culture medium. The use of complex nitrogen sources like soya bean meal, corn steep liquor and yeast extract, which increase the production of antibiotics by Streptomycetes, might be due to slow decomposition of these compounds in the medium. As a result, the use of inorganic nitrogen sources lead to high ammonium concentrations in the culture medium and suppress the antibiotic production in many microorganisms including Streptomyces coelicoflavus BC 01.

\section{Effects of $\mathrm{K}_{2} \mathrm{HPO}_{4}$ on antibiotic production}

The effects of different concentrations of $\mathrm{K}_{2} \mathrm{HPO}_{4}$ on growth and antibacterial metabolite production were studied. Results were shown in Fig. 3. The maximum antibacterial activity was obtained at $0.25 \mathrm{~g} / 100 \mathrm{ml}$ concentration of $\mathrm{K}_{2} \mathrm{HPO}_{4}$, with a biomass of $3.2 \mathrm{mg} / \mathrm{ml}$. The maximum zone of inhibition was observed in P. aeruginosa ( $35.66 \pm 0.47), E$. coli $(35.33 \pm 0.47)$, S. aureus $(35.0 \pm 0.81), P$. vulgaris $(34.66$ $\pm 0.47), B$. cereus $(34.33 \pm 0.47)$ and B. subtilis $(32.66 \pm 0.94)$

Table 2. Effects of different nitrogen sources on growth and antibacterial metabolites production by Streptomyces coelicoflavus BC 01

\begin{tabular}{|c|c|c|c|c|c|c|c|}
\hline \multirow{3}{*}{$\begin{array}{l}\text { Inorganic Nitrogen } \\
\text { sources }(0.4 \% \mathrm{w} / \mathrm{v})\end{array}$} & \multirow{3}{*}{$\begin{array}{l}\text { Growth in dry } \\
\text { weight }(\mathrm{mg} / \mathrm{ml})\end{array}$} & \multicolumn{6}{|c|}{ Zone of inhibition in $\mathrm{mm}$} \\
\hline & & \multicolumn{3}{|c|}{ Gram Positive Bacteria } & \multicolumn{3}{|c|}{ Gram Negative Bacteria } \\
\hline & & S. aureus & B. subtilis & B. cereus & E. coli & P. vulgaris & P. aeruginosa \\
\hline Ammonium citrate & 1.4 & 12 & 11 & 13 & 10 & 11 & 10 \\
\hline Ammonium nitrate & 2.6 & 14 & 16 & 16 & 15 & 17 & 16 \\
\hline Ammonium sulphate & 1.8 & 13 & 13 & 12 & 14 & 13 & 15 \\
\hline Potassium nitrate & 1.3 & 11 & 10 & 11 & 9 & 10 & 11 \\
\hline Sodium nitrate & 1.6 & 12 & 11 & 10 & 11 & 10 & 12 \\
\hline \multicolumn{8}{|c|}{ Organic Nitrogen sources $(0.4 \% \mathrm{w} / \mathrm{v})$} \\
\hline Soya bean meal & 3.2 & 15 & 17 & 18 & 17 & 18 & 18 \\
\hline Peptone & 1.3 & 13 & 12 & 11 & 10 & 12 & 10 \\
\hline Beef extract & 1.8 & 14 & 13 & 14 & 12 & 13 & 12 \\
\hline Yeast extract & 2.2 & 14 & 16 & 15 & 14 & 17 & 16 \\
\hline Tryptone & 1.6 & 13 & 12 & 13 & 15 & 14 & 13 \\
\hline Leucine & 1.4 & 12 & 11 & 10 & 12 & 12 & 11 \\
\hline Histidine & 1.9 & 12 & 15 & 16 & 15 & 14 & 16 \\
\hline Methionine & 1.6 & 13 & 13 & 12 & 14 & 12 & 13 \\
\hline Asparagine & 2.1 & 14 & 15 & 16 & 16 & 16 & 15 \\
\hline Glutamate & 2.4 & 12 & 16 & 17 & 15 & 17 & 16 \\
\hline
\end{tabular}




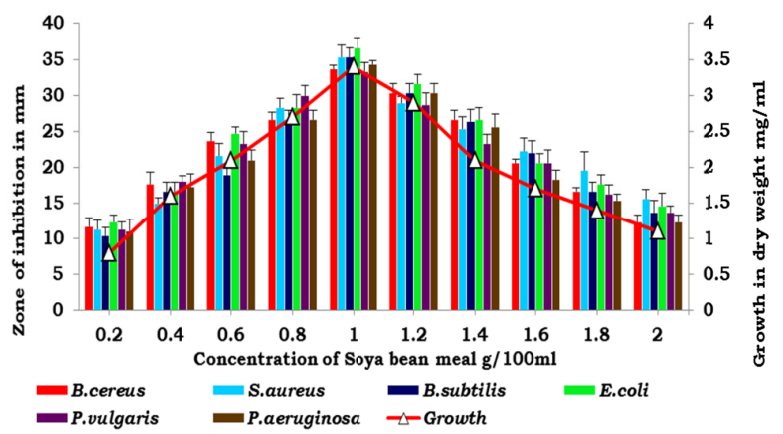

Fig. 2. Effects of soya bean meal on growth and production of antibacterial activity against test organisms in Streptomyces coelicoflavus $\mathrm{BC} 01$

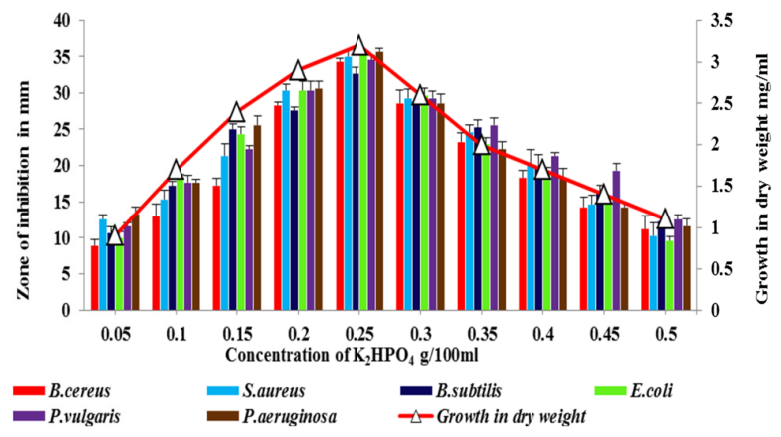

Fig. 3. Effects of $\mathrm{K}_{2} \mathrm{HPO}_{4}$ meal on growth and production of antibacterial activity against test organisms in Streptomyces coelicoflavus $\mathrm{BC} 01$

respectively. From the obtained results $\mathrm{K}_{2} \mathrm{HPO}_{4}$ was optimized at a concentration of $0.25 \mathrm{~g} / 100 \mathrm{ml}$, whereas further increase in the concentration of $\mathrm{K}_{2} \mathrm{HPO}_{4}$ showed negative impact and produced low levels of antibacterial activity and biomass growth. Similar results where low concentration of $\mathrm{K}_{2} \mathrm{HPO}_{4}$ had a positive effect on the antibiotic production was given by Bibb (2005), Martin (2004) and Majumdar and Majumdar (1965). This is because when concentration of inorganic phosphate in the culture media was high, the intracellular concentration of ATP increased and the primary metabolism was accelerated, inhibiting secondary metabolite production. In the present study increasing concentration of $\mathrm{K}_{2} \mathrm{HPO}_{4}$ tended to decrease antibiotic production. Similar reports where phosphate concentrations of more than $10 \mathrm{mM}$ suppressed antibiotic synthesis in most microorganisms were given by Lounes (1996). Aharonowitz and Demain (1977) studied the relation between the concentration of inorganic phosphate in a medium and the production of antibiotics in the fermentation of cephalosporin by Streptomyces clavuligerus; the production was increased when phosphate concentration increased to $25 \mathrm{mM}$. Further addition of phosphate progressively decreased the production. Similar findings were reported by Kishimoto et al. (1996) for production of tetracycline, actinomycin and candicidi.

\section{Effects of $\mathrm{NaCl}$ concentration on antibiotic production}

Salt concentration has a thoughtful effect on the production of antibacterial metabolite from microorganisms due to its effect on the osmotic pressure to the medium
(Pelczer et al., 1993). To observe this effect $\mathrm{NaCl}$ was added to culture media at different concentrations such as $0.2 \%$, $0.4 \%, 0.6 \%, 0.8 \%, 1.0 \%, 1.2 \%, 1.4 \%, 1.6 \% 1.8$ and $2.0 \%$ respectively. The effect of different concentrations of $\mathrm{NaCl}$ on growth and antibacterial metabolite yield was investigated and the results were presented in Fig. 4. The results indicated that $\mathrm{NaCl}$ concentration greatly influenced the production of the antibacterial metabolite. The maximum antibacterial metabolite yield was obtained at $1.0 \mathrm{~g} / 100 \mathrm{ml}$ concentration of $\mathrm{NaCl}$ with a biomass of $3.2 \mathrm{mg} / \mathrm{ml}$ and the maximum zone of inhibitions observed were $B$. cereus $(35.33 \pm 0.94), S$. aureus (33.66 \pm 1.24$), P$. vulgaris $(32.33 \pm 0.47)$, B. subtilis (32.33 \pm 1.24$),$ E. coli $(31.33 \pm 0.47)$ and $P$. aeruginosa $(30.66$ $\pm 1.24)$ at $1.0 \mathrm{~g} / 100 \mathrm{ml}$ concentration of $\mathrm{NaCl}$. The growth of the organism gradually decreased with the increase of $\mathrm{NaCl}$ concentration. Similar types of results were reported by Ripa et al. (2009) in Streptomyces sp. RUPA-08PR and by El-Refai et al. (2011) in Nocardioides luteus where maximum antibiotic production was at $1 \%$ of $\mathrm{NaCl}$ in culture medium. The requirement of $\mathrm{NaCl}$ for the production of bioactive metabolites seems to be different among Streptomyces strains. Saha et al. (2010) reported maximum antibiotic production

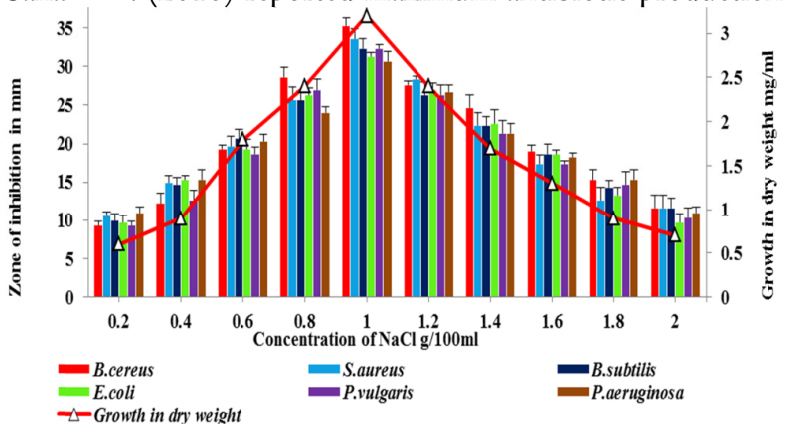

Fig. 4. Effects of $\mathrm{NaCl}$ on growth and production of antibacterial activity against test organisms in Streptomyces coelicoflavus BC 01

by Streptomyces sp. MNK 7 at $5 \%$ of $\mathrm{NaCl}$ and Singh et al. (2009) at $2 \% \mathrm{NaCl}$ by Streptomyces tanashiensis A2D. Salinity levels must be optimized for different growth and production phases, by reducing the sea water levels in media composition, which increase the growth and production.

\section{Effects of temperature on antibiotic production}

Streptomyces coelicoflavus $\mathrm{BC} 01$ showed a narrow range of incubation temperature for a relatively good growth and antibacterial metabolite production. The effect of temperature on growth and antibacterial metabolite production was shown in Fig. 5. The increase of the incubation temperature from $25^{\circ} \mathrm{C}$ to $35^{\circ} \mathrm{C}$ increased the growth of the biomass and the production of the antibacterial metabolite respectively. The maximum antibiotic yield was obtained at $30{ }^{\circ} \mathrm{C}$ with a biomass of $3.8 \mathrm{mg} / \mathrm{ml}$ and the maximum zone of inhibition observed were $P$. aeruginosa $(36.66 \pm 0.94)$, B. subtilis $(36.33 \pm 1.24)$, S. aureus $(34.66 \pm$ $0.94)$, P. vulgaris $(34.33 \pm 0.47)$, E. coli $(35.66 \pm 1.69)$ and $B$. cereus $(35.33 \pm 0.47)$ respectively. From the observed results the temperature was optimized at $30{ }^{\circ} \mathrm{C}$ for antibacterial metabolite production with a biomass of $3.8 \mathrm{mg} / \mathrm{ml}$. The antibacterial activity was decreased consistently with the cell mass by increasing the growth temperature range between 35 - 
156

$50{ }^{\circ} \mathrm{C}$. Even though biomass was deposited at $45^{\circ} \mathrm{C}$ and 50 ${ }^{\circ} \mathrm{C}$, the antibacterial metabolite yield was negligible. Similar findings for production of antibiotics from Streptomyces aureofacines MY18 and Streptomyces roseviolaceus MR13 were reported by Tawfik et al. (1991). Comparable studies by Vastrad and Nelagund (2011), Abdel-Aal et al. (2011) confirmed the optimum temperature of $30^{\circ} \mathrm{C}$ for production of neomycin, kanamycin and anicomycin production by Streptomyces fradiae, Streptomyces kanamyceticus and Streptomyces griseolus respectively. Streptomyces usually produces antibiotics at temperature near $27^{\circ} \mathrm{C}$. Generally, the range of a temperature supporting good growth is as wide as $25^{\circ} \mathrm{C}$, but the temperature range adequate for a good production of secondary metabolites is narrow, of $5 \sim 10^{\circ} \mathrm{C}$. Usually, cultivation for antibiotic production is performed under one constant temperature from the beginning to the end as stated by James and Edwards (1989).

\section{Effects of initialpHon antibiotic production}

The effects of $\mathrm{pH}$ on the growth and antibacterial metabolite production was shown in Fig. 6. The maximum antibacterial activity was obtained at $\mathrm{pH} 7.2$, with a biomass of $3.8 \mathrm{mg} / \mathrm{ml}$ and the maximum zone of inhibition observed were $P$. aeruginosa $(36.33 \pm 1.24)$, B. subtilis (35.66 \pm 1.24$)$, B. cereus $(35.33 \pm 1.69)$, $P$. vulgaris $(34.0 \pm 1.69)$, E. coli $(34.66 \pm 2.05)$ and $S$. aureus $(32.66 \pm 0.47)$ respectively. The change in the $\mathrm{pH}$ of the production medium below and above the optimum conditions resulted in biomass growth, but decreased the antibacterial metabolite yield (Fig. 6). The results show that the isolate was capable to produce antibiotic within the optimum $\mathrm{pH}$ range

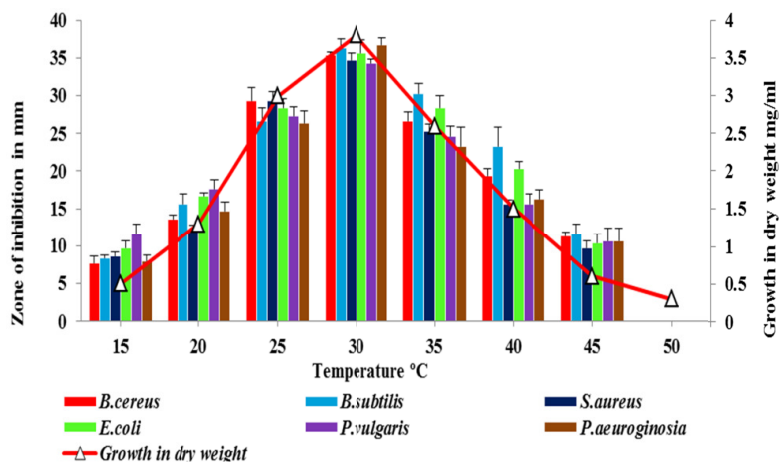

Fig. 5. Effects of temperature on growth and production of antibacterial activity against test organisms in Streptomyces coelicoflawus BC 01

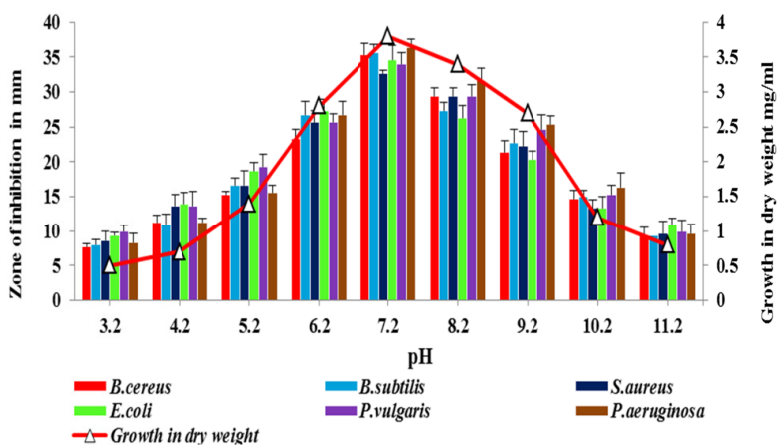

Fig. 6. Effects of $\mathrm{pH}$ on growth and production of antibacterial activity against test organisms in Streptomyces coelicoflavus BC 01
(7.2-8.2) although the strain withstands a broad range of $\mathrm{pH}$ (5.2-10.2). The isolate Streptomyces coelicoflavus BC 01 was optimized at $\mathrm{pH} 7.2$ in the culture medium. The effect of $\mathrm{pH}$ is one of the vital physiological factors, which influence not only the growth, but also the production of antibiotics. The balanced use of the carbon and nitrogen sources will form a basis for $\mathrm{pH}$ control, as buffering capacity is provided by the proteins, peptides and amino acids in the medium. Most of the bacterial strains have their optimum growth on neutral environment. As a result, most of the antibiotics are optimally produced in $\mathrm{pH}$ close to 7.0. For instance, granaticin production was the highest when initial $\mathrm{pH}$ of cultural medium was adjusted to 6.5-7.0 (James et al., 1991). A similar finding was reported by Bystrykh et al. (1996) in Streptomyces coelicolor for actinorhodin. The existence of high concentrations of glucose in the production medium makes it acidic in nature. As the fermentation progress, the cell mass increase by utilizing the nutrients, and thus depletion of nutrients make the medium alkaline in nature (Basak and Majumdar, 1973; Bhuyan, 1962). Hence, the $\mathrm{pH}$ of culture medium for the production of antibiotics must be neutral in Streptomyces coelicoflavus BC 01.

\section{Effects of incubation period on antibiotic production}

The growth of Streptomyces coelicoflavus BC 01 and the production of antibacterial metabolite were monitored over a period of 6 days. The fermentation samples were withdrawn periodically and assayed in order to study the optimal incubation time for production. The effects of different incubation periods on antibiotic yield were shown in Fig. 7. The antibacterial metabolite production by Streptomyces coelicoflavus BC 01 occurred in a growth-phase dependent manner and the highest antibacterial metabolite yield was obtained in the late exponential phase and the stationary phase. The results indicated that the maximum antibacterial activity was obtained at 96 hours incubation period with a biomass of $3.2 \mathrm{mg} / \mathrm{ml}$ and the maximum zone of inhibition observed were B. cereus (35.66 \pm $0.94), E$. coli $(34.67 \pm 2.49), P$. aeruginosa $(34.66 \pm 0.94), P$. vulgaris $(34.33 \pm 1.69)$, B. subtilis $(33.67 \pm 1.24)$ and $S$. aureus $(33.0 \pm 0.81)$ respectively. The results showed that incubation period of Streptomyces coelicoflavus BC 01 for antibacterial metabolite production was optimized at 96 hours. The incubation time for the production of antibacterial metabolite seems to be different among Streptomyces strains. From the present study incubation time of 96 hours was best suited for antibacterial metabolite production. Thakur et al. (2009) reported that antibacterial metabolites elaborated from 144

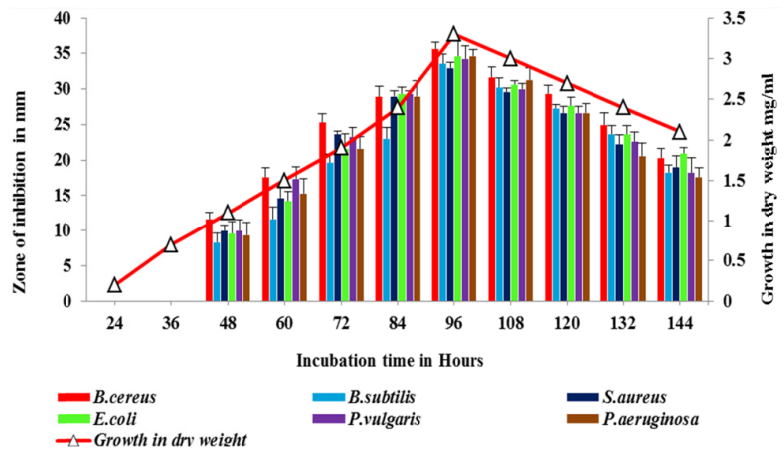

Fig. 7. Effects of incubation on growth and production of antibacterial activity against test organisms in Streptomyces coelicoflavus BC 01 
hours old culture of Streptomyces sp. 201 showed worthy antimicrobial activity. Secondary metabolites collected from 168 hours old culture of Streptomyces tanashiensis strain A2D exhibited worthy antimicrobial activity as reported by Singh $e t$ al. (2009). Similar results were observed for streptomycin production in batch cultures of Streptomyces griseus ATCC 12475 when they were grown in a mineral medium by Fazeli $e t$ al. (1995) and for the production of candicidin in liquid grown cultures of Streptomyces griseus by Martin and McDaniel (1975).

\section{Effects of agitation on antibiotic production}

The agitation provides greater aeration to the culture and also creates conditions for greater availability of nutrients to the cells. Hence, the effect of agitation on growth and antibacterial metabolite production was determined and showed in Fig. 8. The highest antibacterial activity was observed at $160 \mathrm{rpm}$ with the biomass of $3.2 \mathrm{mg} / \mathrm{ml}$ and the maximum zone of inhibition observed were E. coli $(40 \pm 0.81), S$. aureus $(40.6 \pm 0.43), P$. aeruginosa (41.23 \pm 0.71$), P$. vulgaris ( $40.50 \pm 0.40), B$. cereus $(41.0 \pm 0.81)$ and $B$. subtilis $(40.5 .0 \pm 0.40)$ respectively. At 160 rpm Streptomyces coelicoflavus BC 01 was optimized to get the best antibacterial yield, although at $180-200 \mathrm{rpm}$ the antibiotic activity was moderate. Further increase in the agitation speed decreased the antibacterial activity along with biomass. Thus the results revealed that the antibacterial metabolite yield and the

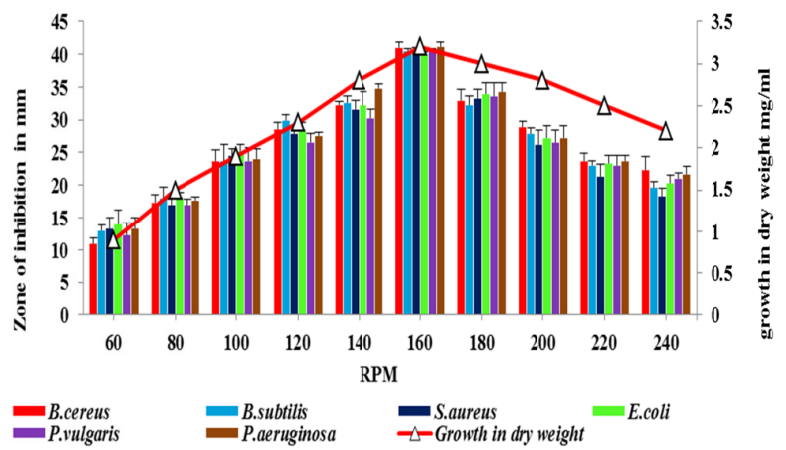

Fig. 8. Effect of agitation speed (rpm) on growth and production of antibacterial activity against test organisms in Streptomyces coelicoflavus $\mathrm{BC} 01$

growth rate were associated with agitation speed. Most of the antibiotic producing microorganisms are aerobic microorganism. Therefore oxygen supply has a great impact on their growth and antibiotic production. The decrease in antibiotic productivity was observed at both lower and higher agitation speeds. In the present study agitation speed of $160 \mathrm{rpm}$ yielded biomass of 3.2 $\mathrm{mg} / \mathrm{ml}$. Although agitation is usually considered only from the viewpoint of oxygen, it may have other effects. The increase in agitation speed might affect the cellular damage and therefore decreases the product yield. The oxygen limitation acts in an analogous manner to substrate limitation imposed by dissolved nutrients, stimulating secondary metabolite production in some cases and inhibiting it in others as stated by Clark et al. (1995).

\section{The optimized media after fermentation conditions}

The medium optimized in the present investigation for the maximum production of antibacterial metabolite by Streptomyces coelicoflavus BC 01 has the following composition: $12.0 \mathrm{~g} / \mathrm{L}$ glucose; $10.0 \mathrm{~g} / \mathrm{L}$ soya bean meal; 2.5 $\mathrm{g} / \mathrm{L} \mathrm{K}_{2} \mathrm{HPO}_{4} ; 1.0 \mathrm{~g} / \mathrm{L} \mathrm{NaCl}$; trace salt solution $1.0 \mathrm{ml}$

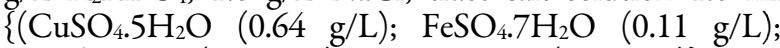
$\left.\mathrm{MnCl}_{2} .4 \mathrm{H}_{2} \mathrm{O}(0.79 \mathrm{~g} / \mathrm{L}) ; \mathrm{ZnSO}_{4} .7 \mathrm{H}_{2} \mathrm{O}(0.15 \mathrm{~g} / \mathrm{L})\right\}$ at 30 ${ }^{\circ} \mathrm{C}$ for 96 hours at $160 \mathrm{rpm}$. The present study results evidenced that the antibacterial productivity employing optimized fermentation conditions was higher than the initial fermentation conditions.

\section{Conclusions}

The present study focused mainly on the optimization of nutritional constituents and culture conditions for production of antibacterial metabolites in Streptomyces coelicoflavus BC 01 by altering one parameter at a time. It has been observed that antibacterial metabolite yield depends not only on the nature of the strain, but also on the composition of carbon and nitrogen sources, inorganic phosphorous, cell density, aeration and agitation conditions. Significant increase in the biomass and yield was attained by using newly formulated production medium under optimized cultural conditions. Therefore, large scale fermentation medium can be planned under these optimized parameters, to achieve a very good antibiotic yield.

\section{Acknowledgements}

The author (K.V. Raghava Rao) gratefully acknowledges the University Grants Commission (UGC), New Delhi, India, for providing financial assistance under Non-SAP Research fellowship for meritorious students scheme to carry out this research work.

\section{References}

Abdel-Aal TA, Abdelwahed NA, Awad G, El Diwany AI, Haroun BM (2011). Improvement of anisomycin production through mutation and medium optimization for Streptomyces griseolus. Australian Journal of Basic and Applied Sciences 5(12):2637-2648.

Aharonowitz Y, Demain AL (1977). Influence of inorganic phosphate and organic buffers on cephalosporin production by Streptomyces clavuligerus. Archives of Microbiology 115(2):169-173.

Basak K, Majumdar SK (1973). Utilization of carbon and nitrogen sources by Streptomyces kanamyceticus for kanamycin production. Antimicrobial Agents and Chemotherapy 4(1):6-10.

Bhuyan BK (1962). Pactamycin Production by Streptomyces pactum. Applied Microbiology 10(4):302-304.

Bibb MJ (2005). Regulation of secondary metabolism in Streptomyces. Current Opinion in Microbiology 8(2):208-215.

Bruckner R, Titgemeyer F (2002). Carbon catabolite repression in bacteria: choice of the carbon source and autoregulatory limitation of sugar utilization. FEMS Microbiology Letters 209(2):141-148.

Bystrykh LV, Fernander-Moreno MA, Herrema JK, Malportida F, Hopwood DA, Dijkhuizen L (1996). Production of ActinorhodinRelated Blue pigments by Streptomyces coelicolor A3 (2). Journal of Bacteriology 178:2238-2244.

Clark GJ, Langley D, Bushell ME (1995). Oxygen limitation can induce microbial secondary metabolite formation: investigations with miniature electrodes in shaker and bioreactor culture. Microbiology 141(3):663-669. 
158

Dills SS, Apperson A, Schmidt MR, Saier MH Jr (1980). Carbohydrate transport in bacteria. Microbiological Reviews 44(3):385-418.

El-Refai HA, AbdElRahman HY, Abdulla H, Hanna AG, Hashem AH, El-Refai AH, Ahmed EM (2011). Studies on the production of Actinomycin, by Nocardioides luteus, a novel source. Current Trends in Biotechnology and Pharmacy 5(3):1282-1297.

Fazeli MR, Cove JH, Baumberg S (1995). Physiological factors affecting streptomycin production by Streptomyces griseus ATCC 12475 in batch and continuous culture. FEMS Microbiology Letters 126(1):55-62.

Fisher S, Sonnenshein A (1991). Control of Carbon and Nitrogen Metabolism in Bacillus subtilis. Annual Review of Microbiology 45:107-135.

Gesheva V, Ivanova V, Gesheva R (2005). Effects of nutrients on the production of AK-111-81 macrolide antibiotic by Streptomyces hygroscopicus. Microbiological Research 160(3):243-248.

Jakeman DL, Graham CL, Young W, Vining LC (2006). Culture conditions improving the production of jadomycin B. Journal of Industrial Microbiology and Biotechnology 33(9):767-772.

James PDA, Edwards C (1989). The effects of temperature on growth and production of theantibiotic Granaticin by a thermotolerant Streptomycete. Journal of General Microbiology 135(7):1997-2003.

James PDA, Edwards C, Dawson M (1991). The effects of temperature, $\mathrm{pH}$ and growth rate on secondary metabolism in Streptomyces thermoviolaceus grown in a chemostat. Journal of General Microbiology 137(7):1715-1720.

Kishimoto K, Park YS, Okabe M, Akiyama S (1996). Effect of phosphate ion on mildiomycin production by Streptoverticillium rimofaciens. Journal of Antibiotics 49:775-780.

Lin J, Bai L, Deng Z, ZhongJJ (2010). Effect of ammonium in medium on ansamitocin P-3 production by Actinosynnema pretiosum. Biotechnology and Bioprocess Engineering 15(1):119-125.

Lounes A, Lebrihi A, Benslimane C, Lefebvre G, Germain P (1996). Regulation of spiramycin synthesis in Streptomyces ambofaciens: effects of glucose and inorganic phosphate. Applied Microbiology and Biotechnology 45:204-211.

Majumdar MK, Majumdar SK (1965). Effect of minerals on neomycin production by Streptomyces fradiae. Applied Microbiology 13(2):190-193.

Martin JF (2004). Phosphate control of the biosynthesis of antibiotics and other secondary metabolites is mediated by the PhoR-PhoP system: an unfinished story. Journal of Bacteriology 186(16):51975201.

Martin JF, McDaniel LE (1975). Kinetics of biosynthesis of polyene macrolide antibiotics in batch cultures: cell maturation time. Journal of Biotechnology and Bioengineering 17(6):925-938.

Miyadoh S (1993). Research on antibiotic screening in Japan over the last decade: a producing microorganisms approach. Actinomycetologica 7(2):100-106.

Narayana KJP, Vijayalakshmi M (2008). Optimization of antimicrobial metabolites production by Streptomyces albidoflavus. Research Journal of Pharmacology 2(1):47.

Pandey A, Shukla ANUPAM, Majumdar SK (2005). Utilization of carbon and nitrogen sources by Streptomyces kanamyceticus M27 for the production of an antibacterial antibiotic. African Journal of Biotechnology 4(9):909-910.

Postma PW, LengelerJW, Jacobson GR (1993). Phosphoenolpyruvate: carbohydrate phosphotransferase systems of bacteria. Microbiological Reviews 57(3):543-594.

Pridham TG, Gottlieb D (1948). The utilization of carbon compounds by some Actinomycetales as an aid for species determination. Journal of Bacteriology 56:107-114.

Priya AJ, Sagadevan E, Dhanalakshmi P, Kumar SS, Karthikeyan V, Arumugam P (2012). Detection of antioxidant and antimicrobial activities in marine actinomycetes isolated from Puducherry coastal region. Journal of Modern Biotechnology 1(2):63-69.

Rao KVR, Rao TR (2013). Molecular characterization and its antioxidant activity of a newly isolated Streptomyces coelicoflavus BC 01 from mangrove soil. Journal of Young Pharmacists 5:121-126.

Ripa FA, Nikkon F, Zaman S, Khondkar P (2009). Optimal conditions for antimicrobial metabolites production from a New Streptomyces sp. RUPA-08PR isolated from Bangladeshi soil. Mycobiology 37(3):211-214.

Ruiz B, Chavez A, Forero A, Garcia-Huante Y, Romero A, Sanchez M, Rocha D, Sanchez B, Rodriguez-Sanoja R, Sanchez S, Langley E (2010). Production of microbial secondary metabolites: Regulation by the carbon source. Critical Reviews in Microbiology 36(2):146-167.

Saha MR, Ripa FA, Islam MZ, Khondkar P (2010). Optimization of conditions and in vitro antibacterial activity of secondary metabolite isolated from Streptomyces sp. MNK 7. Journal of Applied Science Research 6(5):453-459.

Saier MH Jr, Crasnier M (1996). Inducer exclusion and the regulation of sugar transport. Research in Microbiology 147:482-489.

Sanchez S, Chavez A, Forero A, Garcia-Huante Y, Romero A, Sanchez M, Rocha D, Sanchez B, Avalos M, Guzman-Trampe S, RodriguezSanoja R, Langley E, Ruiz B (2010). Carbon source regulation of antibiotic production. Journal of Antibiotics 63:442-459.

Shirling ET, Gottlieb D (1966). Method for characterization of Streptomyces species. In Int J Syst.

Singh LS, Mazumdar S, Bora TC (2009). Optimization of process parameters for growth and bioactive metabolite production by a salt-tolerant and alkaliphilic actinomycete, Streptomyces tanashiensis strain A2D. Journal de Mycologie Medicale 19(4):225-223.

Solanki R, Khanna M, Lal R (2008). Bioactive compounds from marine actinomycetes. Indian Journal of Microbiology 48:410-431.

Sunesson AL, Nilsson CA, Carlson R, Blomquist G, Andersson B (1997). Production of volatile metabolites from Streptomyces albidoflavus cultivated on gypsum board and tryptone glucose extract agar - Influence of temperature, oxygen and carbon dioxide levels. Annals of Occupational Hygiene 41(4):393-413.

Tarhan L, Kayalı HA, Sazak A, Şahin N (2011). The correlations between TCA-glyoxalate metabolite and antibiotic production of Streptomyces sp. M4018 grown in glycerol, glucose, and starch mediums. Applied Biochemistry and Biotechnology 164(3):318-337.

Tawfik KA, Ramadan EM (1991). Factors affecting the biological activity of Streptomyces aureofaciens MY 18 and Str. roseviolaceus MR 13. Journal King Abdul Azis University Science 3:5-19. 
Thakur D, Bora TC, Bordoloi GN, Mazumdar S (2009). Influence of nutrition and culturing conditions for optimum growth and antimicrobial metabolite production by Streptomyces sp. 201. Journal de Mycologie Medicale 19(3):161-167.

Usha N, Masilamani S (2013). Bioactive compounds produced by Streptomyces strain. International Journal of Pharmacy and Pharmaceutical Sciences 5(1):176-178.

Van Wezel GP, Mahr K, König M, Traag BA, Pimentel-Schmitt EF, Willimek A, Titgemeyer F (2005). GlcP constitutes the major glucose uptake system of Streptomyces coelicolor A3(2). Molecular Microbiology 55(2):624-636.

Vasavada SH, Thumar JT, Singh SP (2006). Secretion of a potent antibiotic by salt-tolerant and alkaliphilic actinomycete Streptomyces sannanensis strain RJT-1. Current Science 91(10):1393-1397.

Vastrad BM, Nelagund SE (2011). Optimization and production of neomycin from different agro industrial wastes in solid state fermentation. International Journal of Pharmaceutical Sciences and DrugResearch 3(2):104-111.
Viana DA, Carneiro-Cunha MN, Araujo JM, Barros-Neto B, LimaFilho JL, Converti A, Pessoa-Junior A, Porto ALF (2010). Screening of variables influencing the Clavulanic Acid Production by Streptomyces DAUFPE 3060 strain. Applied Biochemistry and Biotechnology 160(6):1797-1807.

Vilches C, Méndez C, Hardisson C, Salas JA (1990). Biosynthesis of oleandomycin by Streptomyces antibioticus: Influence of nutritional conditions and development of resistance. Journal of General Microbiology 136:1447-1454.

Wu JY, Huang JW, Shih HD, Lin WC, Liu YC (2008). Optimization of cultivation conditions for fungichromin production from Streptomyces padanus PMS-702. Journal of the Chinese Institute of Chemical Engineers 39(1):67-73.

Zhu CH, Lu FP, He YN, Han ZL, Du LX (2007). Regulation of avilamycin biosynthesis in Streptomyces viridochromogenes: effects of glucose, ammonium ion, and inorganic phosphate. Applied Microbiology and Biotechnology 73(5):1031-1038. 